\title{
Characterization of chronic HCV infection in Northwest Spain: Impact of the treatment strategic plan of the Spanish National Health Service on HCV cure
}

\author{
Marta Grandal $^{1}$, Berta Pernas ${ }^{1}$, Ana Mariño ${ }^{2}$, Hortensia Álvarez ${ }^{2}$, Andrés Tabernilla ${ }^{1}$, \\ Ángeles Castro-Iglesias ${ }^{1}$, Álvaro Mena ${ }^{1}$, Manuel Delgado ${ }^{1}$, Sonia Pértega ${ }^{3}$, Eva \\ Poveda $^{1}$ \\ ${ }^{1}$ Grupo de Virología Clínica, Instituto de Investigación Biomédica de A Coruña (INIBIC) - Complejo Hospitalario \\ Universitario de A Coruña (CHUAC), SERGAS Universidad de A Coruña. A Coruña, Spain \\ ${ }^{2}$ Unidad de Enfermedades Infecciosas, Servicio de Medicina Interna, Complejo Hospitalario Universitario de Ferrol \\ (CHUF), SERGAS. Ferrol, Spain \\ ${ }^{3}$ Unidad de Epidemiología Clínica y Bioestadística, Instituto de Investigación Biomédica de A Coruña (INIIBC)- \\ Complejo Hospitalario Universitario de A Coruña (CHUAC). A Coruña, Spain
}

\begin{abstract}
The aim of the study was to characterize HCV infection in Northwest Spain and assess the impact of the Spanish Strategic Plan to cure HCV infection. Overall, 387 patients were included (60.9\% HIV/HCV coinfected and 28.2\% cirrhotic). Of these, $72.9 \%$ of patients that were recognized as priority for HCV treatment according to the Spanish Strategic Plan ( $\geq F 2$, transplant or extrahepatic manifestations), initiated treatment during 2015. Globally, SVR12 was achieved in $96.5 \%$ of patients. The implementation of the Spanish Strategic Plan has been critical to advance in HCV cure, but $27.1 \%$ of priority patients still remain awaiting HCV treatment initiation.
\end{abstract}

\section{Keywords}

$\mathrm{HCV}$ infection, $\mathrm{HCV}$ treatment, HIV/HCV coinfection 


\section{BACKGROUND}

$\mathrm{HCV}$ infection is an important health problem affecting more than 150 million people worldwide and about 475000 people in Spain,[1][2] and can lead to significant morbidity and mortality.[3] The introduction of high-effective and well tolerated direct-acting antivirals (DAA) has allowed for shorter treatment regimens and offered new opportunities for previously excluded groups. Additionally, these newer regimens have shown to be cost-effective across all fibrosis stages.[4, 5] However, their current high cost only allows a restricted number of patients to access treatment. In May 2015, the Spanish National Health Service published a Strategic Plan to face HCV infection. The objective of this Plan was to effectively address the prevention, diagnosis, treatment, and monitoring of $\mathrm{HCV}$-infected patients.[2]

The aim of the study was to characterize HCV infection in Northwest Spain and evaluate the impact of the Spanish Strategic Plan in this population.

\section{MATERIALS AND METHODS}

This is a transversal observational study. Patients with chronic HCV infection in two hospitals of Northwest Spain were included in the period June 2014 to December $2015(n=387)$. This sample size allows to estimate parameters of interest with a confidence interval of $95 \%(\alpha=0.05)$ and a precision $\pm 5 \%$.

The research protocol was approved by the regional ethics committee ("Comité Ético de Investigación Clínica de Galicia," register code 2013/249). All patients participating in the study signed the informed consent.

Epidemiological, clinical, and virological characteristics were recorded. Liver fibrosis was measured by transient elastography. Regimen and duration of treatment were recorded in those patients who initiated HCV treatment during 2015. Treatment efficacy was measured as sustained virological response (SVR12) defined as HCV-RNA below the level of detection recorded 12 weeks after treatment discontinuation.

The statistical analysis was performed using the Statistical Package for the Social Sciences software (SPSS 19.0, Chicago, IL). Categorical variables were presented as number of cases or percentage and compared by $\mathrm{X}^{2}$ test or Fisheŕs exact test, when appropriate. Continuous variables were expressed as median (interquartile range) and compared by non-parametric Mann-Whitney and Kruskal-Wallis test, when appropriate. A $P$-value $<0.05$ was considered statistically significant.

\section{RESULTS}

A total of 387 patients were included. Of these, $72.6 \%$ were men; $60.9 \%(n=223) \mathrm{HIV} / \mathrm{HCV}$ coinfected patients and $28.2 \%(n=100)$ cirrhotic. Epidemiological, clinical, laboratory parameters, and virological characteristics previous to HCV-treatment initiation are shown in Table 1 . Genotype 1 was the most common one (66.2\%) followed by genotype $3(16.8 \%)$. Overall, $4.4 \%$ of patients had previous hepatic decompensation: hydropic decompensation (3.9\%), encephalopathy (1.3\%), and/or gastrointestinal bleeding $(0.8 \%)$. In addition, $1 \%$ of patients had hepatocellular carcinoma and $3.9 \%$ extrahepatic manifestations of HCV infection. Among treatment-experienced (34.4\%) patients, $81.8 \%$ had received pegylated-interferon (Peg-IFN) and ribavirin (RBV) regimen, and $15.2 \%$ PegIFN + RBV + boceprevir/telaprevir. Response to previous HCV treatment was: $31.8 \%$ null response, $25.8 \%$ relapse, $21.2 \%$ intolerance to Peg-IFN + RBV, $10.6 \%$ partial response, and $10.6 \%$ unknown response. 
Table 1. Epidemiological, clinical, and virological characteristics of HCV infection and DAA-regimens used to treat HCV infection during 2015

\begin{tabular}{|c|c|c|c|c|}
\hline Characteristics & $\operatorname{HCVmono}(n=143)$ & $\mathrm{HIV} / \mathrm{HCV}(n=223)$ & $P$ & Total $(n=387)$ \\
\hline Median time with HCV infection (IQR), years & $15(8-19)$ & $18(13-23)$ & $<0.001$ & $17(11-21)$ \\
\hline Median age (IQR), years & $50(43-55)$ & $49(44-53)$ & 0.163 & $49(45-54)$ \\
\hline Male sex $(\%)$ & 75.5 & 74 & 0.742 & 72.6 \\
\hline Route of transmission (\%) & & & $<0.001$ & \\
\hline IDU & 44.8 & 85.7 & & 69.7 \\
\hline Not known & 47.6 & 7.6 & & 23.2 \\
\hline Other & 7.7 & 6.7 & & 7.1 \\
\hline Median AST (IQR), mg/dL & $37(26-59)$ & $42(30-65)$ & 0.051 & $39(28-61)$ \\
\hline Median ALT (IQR), mg/dL & $47(25-88)$ & $46(32-78)$ & 0.595 & $45(29-78)$ \\
\hline $\operatorname{HBsAg}(\%)$ & 0 & 0.5 & 0.999 & 0.3 \\
\hline Prior HCV treatment (\%) & & & 0.901 & \\
\hline Naive & 65.7 & 66.4 & & 65.6 \\
\hline Treatment-experienced & 34.3 & 33.6 & & 34.4 \\
\hline Median HCV-RNA (IQR), $\log 10 \mathrm{UI} / \mathrm{mL}$ & $6.01(5.03-6.48)$ & $6.21(5.59-6.65)$ & 0.007 & $6.13(5.24-6.58)$ \\
\hline IL-28B polymorphism $(\%)$ & & & 0.019 & \\
\hline $\mathrm{CC}$ & 24.3 & 41.5 & & 36.3 \\
\hline $\mathrm{CT}$ & 61.4 & 42.1 & & 47.9 \\
\hline $\mathrm{TT}$ & 14.3 & 16.5 & & 15.8 \\
\hline $\mathrm{HCV}$ genotype (\%) & & & $0.001 *$ & \\
\hline 1a & 43 & 41.7 & & 41.5 \\
\hline $1 b$ & 30.3 & 16.1 & & 23.1 \\
\hline 1 no subtype & 0.7 & 1.3 & & 1.6 \\
\hline 2 & 3.5 & 0.4 & & 1.8 \\
\hline 3 & 13.4 & 20.6 & & 16.8 \\
\hline 4 & 9.2 & 19.7 & & 15.3 \\
\hline Liver fibrosis (\%) & & & 0.364 & \\
\hline F0-F1 & 29.2 & 38.5 & & 34.4 \\
\hline $\mathrm{F} 2$ & 24.6 & 20 & & 22 \\
\hline F3 & 16.9 & 14.6 & & 15.5 \\
\hline F4 & 29.2 & 26.8 & & 28.2 \\
\hline Median liver fibrosis (IQR), KPa & $8.8(6.9-14.5)$ & $8.5(6.1-13.4)$ & 0.299 & $8.7(6.3-14.3)$ \\
\hline $\mathrm{HCV}$ treatment during $2015(\%)$ & 64.3 & 42.4 & $<0.001$ & 52.7 \\
\hline \multicolumn{5}{|l|}{ Regimen of treatment $(\%)$} \\
\hline DAA $($ SOF or SMV) + Peg-IFN + RBV & 6.5 & 0 & & 2.9 \\
\hline $\mathrm{SOF}+\mathrm{DAC} \pm \mathrm{RBV}$ & 14.1 & 25.5 & & 18.6 \\
\hline $\mathrm{SOF}+\mathrm{LDV} \pm \mathrm{RBV}$ & 43.5 & 59.6 & & 51 \\
\hline $\mathrm{SOF}+\mathrm{SMV} \pm \mathrm{RBV}$ & 9.8 & 8.5 & & 10.3 \\
\hline $\mathrm{SOF}+\mathrm{RBV}$ & 6.5 & 0 & & 3.4 \\
\hline $3 \mathrm{D}$ & 15.2 & 2.1 & & 10.3 \\
\hline $2 \mathrm{D}$ & 4.3 & 1.1 & & 3.4 \\
\hline Duration of treatment (\%) & & & $0.103 * *$ & \\
\hline 8 weeks & 1.1 & 0 & & 0.5 \\
\hline 12 weeks & 74.4 & 64.5 & & 70.6 \\
\hline 24 weeks & 24.4 & 35.5 & & 28.9 \\
\hline
\end{tabular}

HCVmono, hepatitis C monoinfection; IQR, interquartile range; IDU, intravenous drug users; AST, aspartate aminotransferase; mg, miligrams; dL, decilitre; ALT, alanine aminotransferase; HBsAg, hepatitis B surface antigen; HCV-RNA, plasmatic viremia of $\mathrm{HCV}$; FO-F4, grade of liver fibrosis measured by transient elastography; KPa, kilopascals; DAA, direct-acting antivirals; SOF, sofosbuvir; SMV, simeprevir; Peg-IFN, pegylated interferon; RBV, ribavirin; DAC, daclatasvir; LDV, ledipasvir; 3D, ombitasvir + paritaprevir/ritonavir + dasabuvir; 2D, ombitasvir + paritaprevir/ritonavir.

*Comparing genotypes $1 \mathrm{a}, 1 \mathrm{~b}, 3$, and 4 .

***Comparing 8-12 versus 24 weeks. 
Regarding HIV/HCV patients, 95.9\% received antiretroviral treatment (ART) with a combination of two nucleoside reverse transcriptase inhibitors and a protease inhibitor (43.8\%), a non-nucleoside reverse transcriptase inhibitor $(28.8 \%)$ or an integrase inhibitor $(13.5 \%)$ while $13.5 \%$ received other regimens. Median CD4 count at the moment of the study was $566(312-750)$ cells $/ \mathrm{mm}^{3}$ and $86.7 \%$ of patients under ART had suppressed viremia.

During 2015, 52.7\% of HCV-infected patients initiated treatment. According to the Spanish Strategic Plan for HCV infection, $66.5 \%$ of all patients should be prioritized for HCV treatment (liver fibrosis $\geq \mathrm{F} 2$, transplant or extrahepatic manifestations). Of these, $72.9 \%$ initiated HCV treatment during 2015. Combinations of DAA and duration of HCV treatment are shown in Table 1.

Overall, 96.5\% of HCV patients achieved SVR12. SVR12 rates in different subgroups are shown in Figure 1. No differences were observed according to previous HCV treatment $(P=0.086), \mathrm{HIV} / \mathrm{HCV}$ coinfection $(P=0.395)$, HCV genotype (1 vs. non-1 genotype, $P=0.999$; and 3 vs. non-3, $P=0.181)$ or liver fibrosis (F2-F3 vs. F4, $P=0.408$ ).
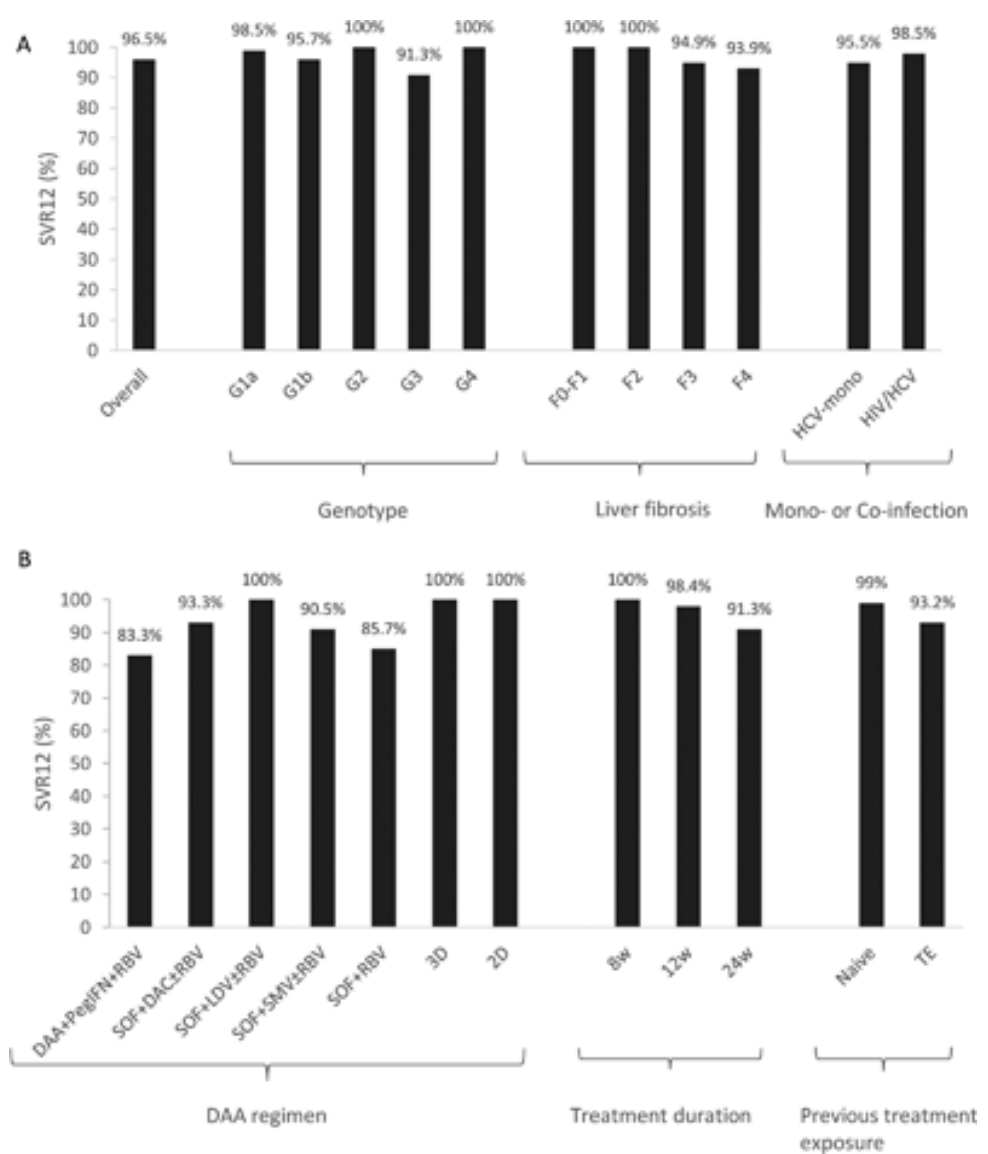

Figure 1. Sustained virological response at 12 weeks (SVR12) after finishing HCV treatment. A: Global SVR12 and SVR12 according to genotype, liver fibrosis and HIV/HCV coinfection. B: SVR12 according to DAA-based regimen, duration of HCV treatment and previous exposure to HCV treatment. G1a, genotype 1a; G1b, genotype 1b; G2, genotype 2; G3, genotype 3; G4, genotype 4; F0-F1, liver fibrosis measured by transient elastography $<7.5 \mathrm{KPa}$; F2, liver fibrosis measured by transient elastography 7.5-9.4 KPa; F3, liver fibrosis measured by transient elastography $9.5-12.5 \mathrm{KPa}$; F4, liver fibrosis measured by transient elastography $>12.5 \mathrm{KPa}$; HCV-mono, HCV monoinfected patients; HIV/HCV, HIV and HCV coinfected patients; DAA, direct-acting antivirals (includes SOF or SMV); PegIFN, pegylated interferon; RBV, ribavirin; SOF, sofosbuvir; DAC, daclatasvir; LDV, ledipasvir; SMV, simeprevir; 3D, ombitasvir + paritapevir/ritonavir + dasabuvir; 2D, ombistasvir + paritaprevir/ritonavir; $8 \mathrm{w}, 8$ weeks of HCV treatment; $12 \mathrm{w}, 12$ weeks of HCV treatment; $24 \mathrm{w}, 24$ weeks of $\mathrm{HCV}$ treatment; TE, previous treatment-experienced $\mathrm{HCV}$ patients 
Among failures $(n=6)$, five were treatment-experienced (Peg-IFN-based regimens), four cirrhotic, and one was HIV/HCV coinfected. Regarding HCV genotypes, there were four patients with genotype 1 (only one with genotype 1a although subtype was not determined in one patient) and two with genotype 3. All failures but two (intolerance to Peg-IFN-based regimen and hepatic decompensation with death) were relapses. Of these, three patients were re-treated (Peg-IFN + RBV + sofosbuvir (SOF) and $\mathrm{SOF}+$ ledipasvir + RBV, and both achieved SVR12 while another is on-treatment with $\mathrm{SOF}+$ daclatasvir $+\mathrm{RBV}$ ) and one patient died before re-treatment due to hepatocellular cancer. Resistance test was performed in only one patient and no resistance mutations were found.

\section{DISCUSSION}

This study characterizes chronic HCV infection in 387 patients in Northwest Spain and the impact of the Spanish Strategic Plan on HCV cure last year. This cohort had 28.2\% of patients with cirrhosis and a high prevalence of HIV/HCV patients (60.9\%). The introduction of the Spanish Strategic Plan in 2015 has allowed to treat half $(52.7 \%)$ of all $\mathrm{HCV}$ patients with different DAA-combinations and SVR12 rates over $96 \%$.

The distribution of $\mathrm{HCV}$ genotypes is similar throughout Western Europe with some local differences.[1, 6-8] The prevalence of HCV infection in Spain is among the highest in Europe and several studies reported genotype 1 as the most common one, similarly to our cohort (66.2\%).[9-11] In addition, $\mathrm{HCV}$ genotypes are usually associated to different routes of transmission. In fact, genotypes 1a, 3, and 4 are more common among intravenous drug users[1, 6-8, 10, 12] and represent $82 \%$ of HIV/HCV patients in our cohort.

Cirrhosis had similar prevalence in both HCV-monoinfected and HIV/HCV patients (29.2\% vs. $26.8 \%$, respectively). Since the widespread introduction of ART regimens, data on the effect of HIV coinfection on liver fibrosis progression and its complications have been controversial.[13-16] An improved control of HIV infection with earlier initiation of a less hepatotoxic ART and higher CD4 counts could explain similar rates of cirrhosis in both $\mathrm{HCV}$-monoinfected and HIV/HCV patients observed in our cohort.

The development of DAA has allowed a significant improvement in rates of SVR12. However, those patients involved in clinical trials tend to have more favorable outcomes than patients in the real-world mainly due to strict patient selection. In our cohort, rates of SVR12 were consistently high across all subgroups evaluated, ranging from $83.3 \%$ to $100 \%$. Cirrhosis and HIV/HCV coinfection had been previously identified as independent predictors of virological failure.[17] However, we found no significant differences in SVR12 based on HIV/HCV coinfection or liver fibrosis. Despite the high rate $(98.5 \%)$ of SVR12 observed in our cohort of HIV/HCV patients, it is noteworthy that less patients have initiated treatment compared with $\mathrm{HCV}$-monoinfected $(42.4 \%$ and $64.3 \%$, respectively). Effectiveness in $\mathrm{HIV} / \mathrm{HCV}$ patients was similar to HCV-monoinfected and concordant with clinical trials and real-world published data.[5, 18] Therefore, HIV/HCV population appear to be no longer a hard-to-treat population and should be treated as HCV-monoinfected patients.[19]

In this scenario, the eradication of HCV infection is a desirable and achievable goal for the next years. A successful treatment results in curing $\mathrm{HCV}$ infection and decreasing the risk of $\mathrm{HCV}$-related complications.[20] However, enthusiasm for efficacy and safety of DAA has been dampened by their high price and some countries have restricted these therapies to advanced-stage patients. This is the case of Spain, where the implementation of the Strategic Plan to face HCV infection recommends the priority of $\mathrm{HCV}$ treatment for those patients with liver fibrosis $\geq \mathrm{F} 2$, transplant or extrahepatic manifestations. According to this, $66.5 \%$ of our cohort should be prioritized and $72.9 \%$ of these patients initiated HCV treatment during 2015.

This study has some limitations. The high prevalence of HIV/HCV coinfected patients could represent a selection bias and safety of HCV treatment was not evaluated. 
In summary, the Spanish Strategic Plan has had a great impact on our medical area because it has allowed to treat half of all $\mathrm{HCV}$-infected patients and almost $75 \%$ of patients who were candidates to prioritize HCV treatment. Effectiveness was very high and similar to that observed in the context of clinical trials, including cirrhotic and HIV/HCV coinfected patients. Therefore, access to DAA will probably allow to avoid HCV-related morbidity and costs of HCV complications.

\section{ACKNOWLEDGMENTS}

This work was supported in part by grants from Fondo de Investigación Sanitaria (CPII14/00014, PI10/02166, PI13/02266, CM15/00233, FI14/00557) and Fundación Profesor Novoa Santos, A Coruña. We would like to thank Biobank of A Coruña (SERGAS) for providing us the technical, ethical, and legal advice necessary for the development of our research.

\section{CONFLICTS OF INTEREST}

All authors declare no conflicts of interest.

\section{REFERENCES}

1. Hajarizadeb B, Grebely J, Dore GJ. Epidemiology and natural history of HCV infection. Nat Rev Gastroenterol Hep. 2013; 10:553-562.

2. Plan estratégico para el abordaje de la hepatitis $C$ en el Sistema nacional de salud. 2015. Available from: http://www.msssi.gob.es/ciudadanos/enfLesiones/enfTransmisibles/docs/plan_estrategico_hepatitis_C.pdf

3. Sandler MD, Lee SS. Revolution in hepatitis C antiviral therapy. Br Med Bull. 2015; 113:31-44.

4. Leidner AJ, Chesson HW, Xu F, Ward JW, Spradling PR, Holmberg SD. Cost-effectiveness of hepatitis C treatment for patients in early stages of liver disease. Hepatology. 2015; 61:1860-1869.

5. Walker DR, Pedrosa MC, Manthena SR, Patel N, Marx SE. Early view of the effectiveness of new direct-acting antiviral (DAA) regimens in patients with hepatitis C virus (HCV). Adv Ther. 2015; 32:1117-1127.

6. Cornberg M, Razavi HA, Alberti A, Bernasconi E, Buti M, Cooper C, Dalgard O, Dillion JF, Flisiak R, Forns X, Frankova S, Goldis A, Goulis I, Halota W, Hunyady B, Lagging M, Largen A, Makara M, Manolakopoulos S, Marcellin P, Marinho RT, Pol S, Poynard T, Puoti M, Sagalova O, Sibbel S, Simon K, Wallace C, Young K, Yurdaydin C, Zuckerman E, Negro F, Zeuzem S. A systematic review of hepatitis C virus epidemiology in Europe, Canada and Israel. Liver Int. 2011; 31:30-60.

7. Esteban JI, Sauleda S, Quer J. The changing epidemiology of hepatitis C virus infection in Europe. J Hepatol. 2008; 48:148-162.

8. Kartashev V, Döring M, Nieto L, Coletta E, Kaiser R, Sierra S, HCV EuResist Study Group. New findings in HCV genotype distribution in selected West European, Russian and Israeli regions. J Clin Virol. 2016; 81:82-89.

9. Echevarria JM, Leon P, Pozo F, Avellon A. Follow-up of the prevalence of hepatitis C virus genotypes in Spain during a nine-year period (1996-2004). Enferm Infec Microbiol Clin. 2006; 24:20-25.

10. Poveda E, Wyles D, Morano L, Pineda JA, García F, GEHEP. News on HIV-HCV coinfection: update from the 2015 GEHEP conference. AIDS Rev. 2015; 17:231-237.

11. Ramos B, Nunez M, Toro C, Sheldon J, García-Samaniego J, Ríos P, Soriano V. Changes in the distribution of hepatitis $\mathrm{C}$ virus (HCV) genotypes over time in Spain according to HIV serostatus: implications for HCV therapy in HCV/HIV-coinfected patients. J Infect. 2007; 54:173-179.

12. Wiessing L, Ferri M, Grady B, Kantzanou M, Sperle I, Cullen KJ, EMCDDA DRID Group, Hatzakis A, Prins M, Vickerman P, Lazarus JV, Hope VD, Matheï C. Hepatitis C virus infection epidemiology among people who inject drugs in Europe: a systematic review of data for scaling up treatment and prevention. PLoS ONE. 2014; 9:e103345.

13. Arends JE, Lieveld FI, Boeijen LL, de Kanter CT, van Erpecum KJ, Salmon D, Hoepelman AI, Asselah T, Ustianowski A. Natural history and treatment of HCV/HIV coinfection: is it time to change paradigms. J Hepatol. $2015 ; 63: 1254-1262$.

14. Graham CS, Badem LR, Yu E, Mrus JM, Carnie J, Heeren T, Koziel MJ. Influence of human immunodeficiency virus infection on the course of hepatitis C virus infection: a meta-analysis. Clin Infect Dis. 2001; 33:562-569.

15. Grünhage F, Wasmuth JC, Herkenrath S, Vidovic N, Goldmann G, Rockstroh J, Lammert F, Oldenburg J, Sauerbruch T, Spengler U. Transient elastography discloses identical distribution of liver fibrosis in chonic hepatitis C between HIV-negative and HIV-positive patients on HAART. Eur J Med Res. 2010; 15:139-144.

16. Sterling RK, Wegelin JA, Smith PG, Stravitz RT, Luketic VA, Fuchs M, Puri P, Shiffman ML, Contos MA, Mills AS, Sanyal AJ. Similar progression of fibrosis between HIV/HCV-infected and HCV-infected patients: Analysis of paired liver biopsy samples. Clin Gastroenterol Hepatol. 2010; 8:1070-1076.

17. Arias A, Aguilera A, Soriano V, Benítez-Gutiérrez L, Lledó G, Navarro D, Treviño A, Otero E, Peña JM, Cuervas-Mons V, de Mendoza D. Rate and predictors of treatment failure to all-oral HCV regimens outside clinical trials. Antivir Ther. 2016; doi: 10.3851/IMP3961 [Epub ahead of print]. 
18. Zoulim F, Liang TJ, Gerbes AL, Aghemo A, Deuffic-Burban S, Dusheiko G, Fried MW, Pol S, Rockstroh JK, Terrault NA, Wiktor S. Hepatitis C virus treatment in the real world: optimising treatment and access to therapies. Gut. 2015; 64:1824-1833.

19. Saeed S, Strumpf EC, Walmsley SL, Rollet-Kurhajec K, Pick N, Martel-Laferrière V, Hull M, Gill MJ, Cox J, Cooper C, Klein MB, Canadian Co-Infection Cohort Study. How generalizable are the results from trials of direct activiral agents to people coinfected with HIV/HCV in the real world? Clin Infect Dis. 2016; 62:919-926.

20. Simmons B, Saleem J, Heath K, Cooke GS, Hill A. Long-term treatment outcomes of patients infected with hepatitis $C$ virus: a systematic review and meta-analysis of the survival benefit of achieving a sustained virological response. Clin Infec Dis. 2015; 61:730-740. 